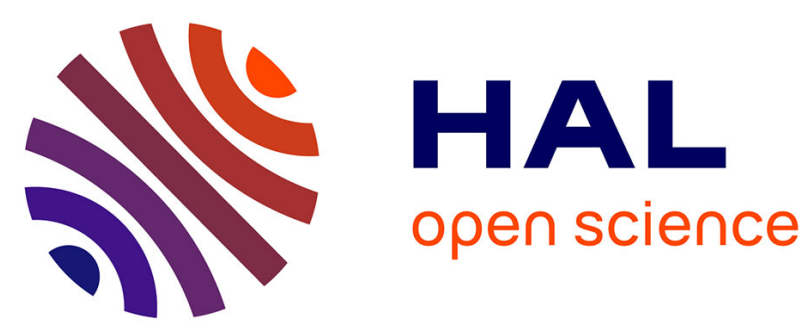

\title{
Remote triggering of air-gap discharge by a femtosecond laser filament and postfilament at distances up to $80 \mathrm{~m}$ O. G Kosareva, D. V Mokrousova, N. A Panov, I. A Nikolaeva, D. E Shipilo, E. V Mitina, A. V Koribut, G. E Rizaev, A. Couairon, Aurélien Houard, et al.
}

\section{- To cite this version:}

O. G Kosareva, D. V Mokrousova, N. A Panov, I. A Nikolaeva, D. E Shipilo, et al.. Remote triggering of air-gap discharge by a femtosecond laser filament and postfilament at distances up to $80 \mathrm{~m}$. Applied Physics Letters, 2021, 119 (4), pp.041103. 10.1063/5.0057544 . hal-03312461

HAL Id: hal-03312461

https://hal-ensta-paris.archives-ouvertes.fr/hal-03312461

Submitted on 2 Aug 2021

HAL is a multi-disciplinary open access archive for the deposit and dissemination of scientific research documents, whether they are published or not. The documents may come from teaching and research institutions in France or abroad, or from public or private research centers.
L'archive ouverte pluridisciplinaire HAL, est destinée au dépôt et à la diffusion de documents scientifiques de niveau recherche, publiés ou non, émanant des établissements d'enseignement et de recherche français ou étrangers, des laboratoires publics ou privés. 


\title{
Remote triggering of air-gap discharge by a femtosecond laser filament and postfilament at distances up to $80 \mathrm{~m}$
}

\author{
O. G. Kosareva, ${ }^{1,2, a)}$ D. V. Mokrousova, ${ }^{2}$ N. A. Panov, ${ }^{1,2}$ I. A. Nikolaeva, ${ }^{1,2}$ D. E. Shipilo, ${ }^{2}$ E. V. Mitina, ${ }^{1}$ \\ A. V. Koribut, ${ }^{2}$ G. E. Rizaev, ${ }^{2}$ A. Couairon, ${ }^{3}$ A. Houard, ${ }^{4}$ A. B. Savel'ev, ${ }^{1,2}$ L. V. Seleznev, ${ }^{2}$ A. A. Ionin, ${ }^{2}$ and \\ S. L. Chin $^{5}$ \\ 1) Faculty of Physics, Lomonosov Moscow State University, Leninskie Gory, Moscow 119991, \\ Russia \\ ${ }^{2)}$ P. N. Lebedev Physical Institute of the Russian Academy of Sciences, 53 Leninskiy prospect, Moscow 119991, \\ Russia \\ ${ }^{3)}$ CPHT, CNRS, Ecole Polytechnique, Institut Polytechnique de Paris, Route de Saclay, F-91128 Palaiseau, \\ France \\ 4) LOA, ENSTA Paris, CNRS, Ecole polytechnique, Institut Polytechnique de Paris, 828 Bd des Maréchaux, 91762 Palaiseau, \\ France \\ ${ }^{5)}$ Center for Optics, Photonics and Lasers (COPL), Laval University, Quebec City, Quebec G1V OA6, \\ Canada
}

(Dated: 6 July 2021)

\begin{abstract}
We experimentally observed a laser-induced remote high-voltage discharge triggering between two needle electrodes with half-a-cm spacing. The discharge was initiated by a 744-nm, 90-fs, 6-mJ laser pulse undergoing filamentation in air. For the direct voltage below the self-breakdown threshold, triggering of air-gap discharge was synchronized with $10-\mathrm{Hz}$ laser repetition rate and occurred between 40 and $80 \mathrm{~m}$ of the propagation path. No discharge guiding was observed. The experimentally registered and simulated remote triggering probability was above $80 \%$ in the range of $40-65 \mathrm{~m}$ from laser output, and about $50 \%$ in the range of $65-80 \mathrm{~m}$. The probability decreases as the postfilament hot spot diverges with simultaneous increase of stochastic laser beam wandering.
\end{abstract}

Laser induced discharge has a lot of applications in different areas of science and technology. Discharge initiation is crucial in the systems where precise synchronization of different electrical processes is needed. For instance, lasertriggered switches are very useful in laser systems where the active medium is pumped by independent sources (as in $\mathrm{KrF}$ laser facility GARPUN ${ }^{1}$ ). Indeed, the spark gap triggered by a femtosecond laser filament in air combines the advantages of large interelectrode air gaps capable of switching high voltages and low subnanosecond jitter of narrow spark gaps $^{2}$. Likewise laser induced discharges seem to be very promising for the fuel ignition of rocket engines ${ }^{3}$ and cryogenic thrusters ${ }^{4,5}$. Another important feature of laser induced electric discharges is their ability to channel a lot of electrical energy at high currents ${ }^{6}$. This effect can be applied to solve the problem of friction in high-speed train's power supply ${ }^{7}$ : in Ref. 8 such discharges were suggested to replace the pantographs of the trains. Laser induced plasma not only commutes the electrodes by ignition of the electric discharge, but also gives an opportunity of controlling the time interval of vacuum gap closure ${ }^{9}$.

After the discovery of self-focusing and laser air breakdown, the laser pulses were proposed to trigger and guide electric discharges ${ }^{10-14}$. The use of laser pulses for lightning protection ${ }^{15}$ was patented ${ }^{16}$ and carried out with a combination of two-arm $\mathrm{CO}_{2}, \mathrm{Nd}$ :glass, and $\mathrm{Nd}$ :YAG high power lasers with tens of nanosecond pulse duration ${ }^{17}$. The $\mathrm{CO}_{2}$ laser induced the plasma on a dielectric target at the top of the lightning tower, while the fourth harmonic of the YAG laser

\footnotetext{
a)Electronic mail: kosareva@physics.msu.ru
}

produced weakly ionized plasma channels far above the target to guide a leader towards thunderclouds ${ }^{17}$. Only two cases of laser-triggered lightning were recorded from the extensive material accumulated ${ }^{17}$ in the years 1997-99.

The development of the Chirped Pulse Amplification technology led to the observation of filamentation ${ }^{18}$ of collimated femtosecond laser pulses in 1995. In the same year, new schemes based on the extended plasma channels formed by femtosecond laser pulses were proposed for lightning protection $^{19,20}$. Several groups worldwide performed experiments to trigger high-voltage discharges with femtosecond pulses $^{21-26}$. Laboratory experiments evidenced triggered and guided discharges over meter-scale distances ${ }^{21,23,27,28}$. Experiments on lightning in the atmosphere rely on the potentially significant ionization induced by multiple filaments over a typical length of $100 \mathrm{~m}$, a few hundreds of meters above the ground. A statistically significant number of electric events synchronized with the laser pulses of high-power Teramobile $^{29}$ facility was reported after real-scale experiments ${ }^{30}$. This research is continued nowadays, and a laser lightning rod based on the plasma and the low-density channel produced by a filament of $1.03-\mu \mathrm{m}, \sim 1-\mathrm{ps}$, Joule-level and high repetition rate laser is under investigation ${ }^{31}$.

An overwhelming majority of research on discharge triggering was implemented with focused laser beams, which limited the range of application of such switches. The plasma formed in the focus either connects the electrodes with the conducting plasma channel ${ }^{21,25,26}$ or heats the gas, leaving a low-density air channel after expansion of the hot region ${ }^{22,32}$. Both cases limit the range of possible discharge triggering to the region with a sufficient number of free electrons. This is very convenient in the case of focusing geometry, because external geometrical focusing determines the position of a fil- 
ament and, consequently, that of the plasma channel. In the collimated geometry, beam pointing instability as well as air turbulence lead to fluctuations of the filament $\operatorname{start}^{33}$ and make it hard to obtain a plasma channel at the desired distance.

At the same time, comparatively weak intensities can trigger discharge without guiding it ${ }^{19}$. Both triggering and guiding can occur for a lower voltage than the self-breakdown voltage. Most often, a discharge can be simply triggered by generating a localized plasma in the gap between the two electrodes, for instance, by focusing a femtosecond laser pulse ${ }^{22}$. In contrast, a laser guided discharge requires a predefined path connecting the electrodes, where the mean free path of electrons is larger than in the surrounding region. The hot column of air left by a femtosecond pulse in its wake plays this role. In this case, a guided discharge is observed for a shorter delay (a few tens of nanoseconds, depending on the gap and applied voltage ${ }^{22,34}$ ) after the triggering pulse than for an unguided discharge (up to several microseconds ${ }^{22}$ ). So, depending on the filament geometry relative to the electrodes, the discharge may be guided ${ }^{19,21-23,35}$, even along a curve ${ }^{32,36}$, partly guided $^{23,27}$, or just triggered ${ }^{22}$.

In this work we remotely trigger an electric discharge between two needle electrodes placed along a 100-m-long path with a femtosecond laser pulse propagating in a single filament regime. The discharge was observed between electrodes located anywhere within the high-intensity region, a distance from $40 \mathrm{~m}$ to $80 \mathrm{~m}$ away from the laser. At the distances $45-60 \mathrm{~m}$, the probability of the discharge is $80 \%$, for longer distances it decreases while remaining about $50 \%$. The orientation of the needle electrodes relatively to the beam propagation direction did not affect the discharge occurrence. The discharge triggering at a certain distance is associated with a high-intensity laser beam area of about $1 \mathrm{~mm}^{2}$ [Fig. 1(a)] hitting the cathode and generating photoelectrons from its metal surface as predicted in Ref. 37. Three-dimensional carrier wave resolved numerical simulations on a $100-\mathrm{m}$ path in air show that the intensity threshold of $\sim 0.5 \mathrm{TW} / \mathrm{cm}^{2}$ should be overcome to trigger a discharge in the long-range experiment.

The experiments were carried out using the pulses from a commercial Ti:Sapphire laser system (Avesta Ltd.) with a central wavelength of $744 \mathrm{~nm}$, a pulse duration of $90 \mathrm{fs}$ (FWHM), pulse energy up to $6 \mathrm{~mJ}$ and a repetition rate of $10 \mathrm{~Hz}$. The beam was elliptical with the ratio of 0.4 between the semiaxes and the length of the major axis $\left(\mathrm{FW} e^{-1} \mathrm{M}\right)$ of $8 \mathrm{~mm}$. This beam was directed to the $\sim 100$-m corridor inside the building using several highly reflective interference mirrors (the details are given in Ref. 38). The mirror system introduced a slight divergence to the laser beam (the focal length of the system was estimated as $-50 \mathrm{~m}$ ) thus increasing the distance of the beam collapse to $40-50 \mathrm{~m}$. According to our previous analysis ${ }^{38}$, the single filament consisted in a short (about $0.3-\mathrm{m}$ ) region of high intensity located at $z \sim 50 \mathrm{~m}$ with plasma of density in excess of $10^{16} \mathrm{~cm}^{-3}$, followed by a long postfilament channel without plasma but an intensity in excess of $0.5 \mathrm{TW} / \mathrm{cm}^{2}$. Single "self-cleaned" hot spot surrounded by wide elliptical background was observed from 50 to $100 \mathrm{~m}$, see Ref. 38 and Fig. 1(a).

The discharge triggering system consisted of two needle
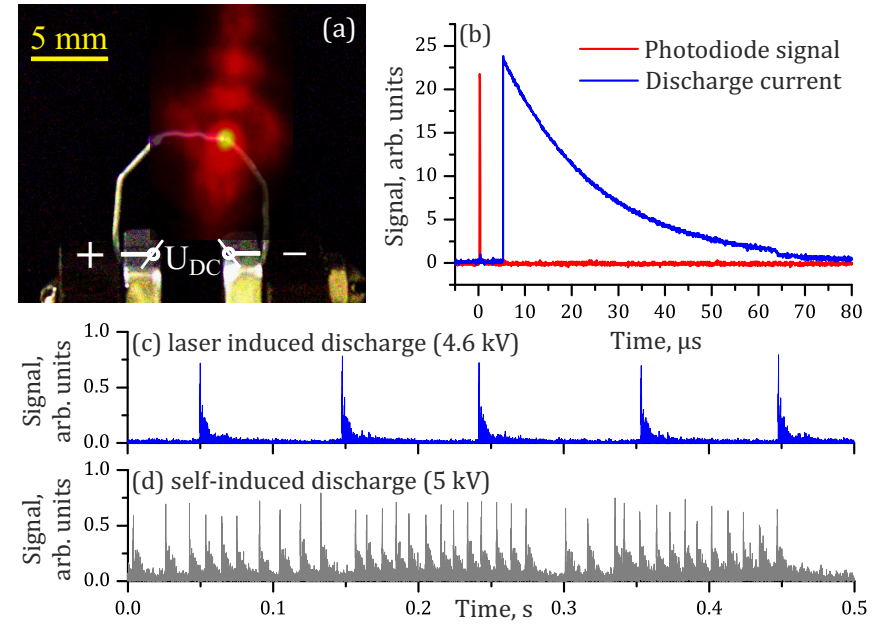

FIG. 1. (a) Photo of the needle electrodes connected by a discharge. The profile of beam luminescence from a paper screen in false color scale taken by CCD-camera at $75 \mathrm{~m}$ from the laser system is superimposed over the cathode in the same spatial scale. The postfilament hot spot (a few TW/ $\mathrm{cm}^{2}$ ) appears as a 1.2-mm yellow circle. (b) Photodiode signal (red curve) and discharge current (blue) registered by oscilloscope. (c,d) Audio signal recorded by microphone while multiple successive (c) laser- and (d) self-induced discharges occurred.

steel electrodes whose tips are facing each other, separated by 4-5 mm [Fig. 1(a)]. The diameter of the electrode's needles was about $0.5 \mathrm{~mm}$. The surface of the tips is irregular and sharp points can appear and disappear due to the damage caused by high-voltage discharge. The laser pulse propagated either perpendicular [Fig. 1(a)] or parallel to the line connecting the tips of the electrodes and hit the cathode.

The high-voltage supply supported the direct voltage up to $10 \mathrm{kV}$, which dropped down during the discharge occurrence only and regained after the discharge current termination. When the voltage between the electrodes was higher than the self-breakdown one of $\sim 4.8 \mathrm{kV}$, the arc appeared independently of a laser shot, that is, even if we blocked the beam. The self-induced discharge events were generated with the frequency of $(80 \pm 30) \mathrm{Hz}$ [Fig. 1(d)], which is much larger than the laser repetition rate of $10 \mathrm{~Hz}$. To study the laserinduced discharge, we set the voltage 100-500 V below the self-breakdown threshold. In that case, the discharge events appeared at the laser repetition rate [Fig. 1(c)].

The discharge current was detected by an oscilloscope. Behind the electrodes we placed a paper screen to block the laser beam while a photodiode responded to the light scattered from this screen. The signal from the photodiode was a synchronization pulse for the oscilloscope. We considered the electric discharge as the laser driven one if only the discharge current was synchronized with the signal from the photodiode [see Fig. 1(b), a typical delay between the photodiode signal and the current onset was less than $25 \mu \mathrm{s}$ ] and checked regularly the absence of discharge when we blocked the laser beam.

Discharge triggering was observed at the distances $z$ from 40 to $80 \mathrm{~m}$ from the laser system output [Fig. 2(a), dashed rectangle]. The measured beam radius at the specific distances 
of the discharge observation is marked with stars in Fig. 2(a). The discharge occurred when the laser beam hit the cathode for any orientation of the line connecting the needle tips, either perpendicular or parallel to the laser beam propagation direction. When the line connecting the tips was parallel to the propagation direction and the anode was closer to the laser (so, that it shadowed the cathode), the discharge was triggered less often (approximately once in 10 shots) than in all the other configurations when the laser beam hit the cathode directly. The straightening of the arc, which is the characteristic indication of the guided discharge ${ }^{19,35}$, was never observed. Thus, at all distances $z$ studied, the discharge was triggered but not guided, see Fig. 1(a).

In the range of distances $z=45-60 \mathrm{~m}$ the discharge was observed at almost every laser shot for an applied voltage close to the breakdown voltage of $\sim 4.8 \mathrm{kV}$. At $z=54 \mathrm{~m}$, we measured, out of 50 laser shots, the probability to initiate the discharge as a function of the applied voltage [Fig. 3(a)]. For the voltages of $4.6-4.7 \mathrm{kV}$ this probability reached $80 \%$ revealing reasonable efficiency for the laser-triggered remote discharge.

Numerical simulations in the conditions of our experiment on a $100-\mathrm{m}$ path were carried out to quantify the pulse intensity distribution in the filament and postfilamentation channel. We used the Forward Maxwell equation (FME, paraxial propagation equation for carrier-wave-resolved fields ${ }^{39,40}$ ) in axially-symmetrical geometry $(t, r)+z$ due to the moderate pulse powers in our experiment. The nonlinear source term in FME includes transient photocurrent as well as the thirdorder instantaneous and delayed nonlinearities. The details about numerical grids required to capture finely the supercontinuum that diverges in the transverse domain and get delayed in time can be found in Ref. 38 .

These simulations in the conditions of our long-range experiment demonstrate that in the 40-m discharge triggering zone the pulse peak intensity is higher than $0.5 \mathrm{TW} / \mathrm{cm}^{2}$. This numerically obtained intensity range agrees well with the intensity estimated from the experiment [Fig. 2(b), cf. the black solid curve to dots and stars]. We substituted the experimentally measured beam radius $r$ [Fig. 2(a), stars and dots] into the equation $I=2 W \sqrt{\ln 2} /\left(\pi^{3 / 2} r^{2} \tau\right)$ and for the pulse energy of $W=6 \mathrm{~mJ}$ as well as the initial FWHM pulse duration $\tau=90$ fs obtained the intensity $I$ shown by dots and stars in [Fig. 2(b)]. This value is by far lower than the clamped intensity ${ }^{41}$ of $\sim 50 \mathrm{TW} / \mathrm{cm}^{2}$ and is not enough to ionize air efficiently. In the simulations, the discharge triggering zone, except for the $0.3-\mathrm{m}$ filament at $z \approx 48 \mathrm{~m}$, is characterized by the intensity in the range from 0.5 to $10 \mathrm{TW} / \mathrm{cm}^{2}$. The corresponding range of plasma density is from $\sim 10^{3}$ to $\sim 10^{11} \mathrm{~cm}^{-3}$, respectively (cf. with a typical natural ion density of $10^{2}-10^{4} \mathrm{~cm}^{-3}$ in air in urban areas ${ }^{42}$ ). Therefore, except for the $0.3-\mathrm{m}$ plasma region, the laser pulse does not generate enough electrons to heat the air and does not create a straight preferred path for the discharge leader by the conducting plasma channel ${ }^{23}$. Heating by the discharge arc itself does not happen since the post-arc temperature decay is faster ${ }^{43,44}$ than $100 \mathrm{~ms}$.

The central high-intensity part of the laser beam propagating in the discharge triggering zone is $1-2 \mathrm{~mm}$ in diameter and

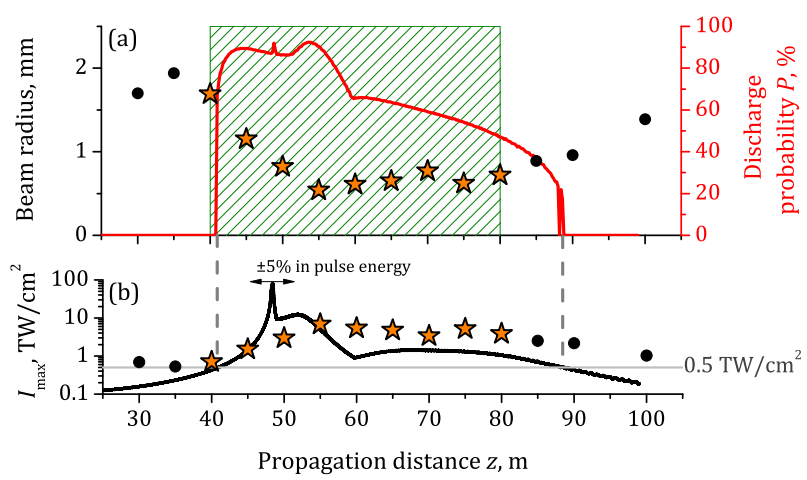

FIG. 2. (a) Dots and stars represent the measured dependence of the beam radius along the propagation direction $z$ (left axis). Stars represent the positions where the discharge was reliably triggered. In accordance with confident triggering events, the dashed rectangle forms a 40-m discharge triggering zone. Red solid curve (right axis) is the calculated probability of the discharge triggering. (b) Dots and stars represent the intensity dependence on the distance $z$ estimated from the measured beam radius in panel (a). Solid curve is the intensity obtained from the $3 \mathrm{D}+$ time simulations on a $100-\mathrm{m}$ propagation path. The initial pulse energy fluctuations in the experiment introduce $\mathrm{a} \pm 3 \mathrm{~m}$ displacement of this curve along the $z$ direction.
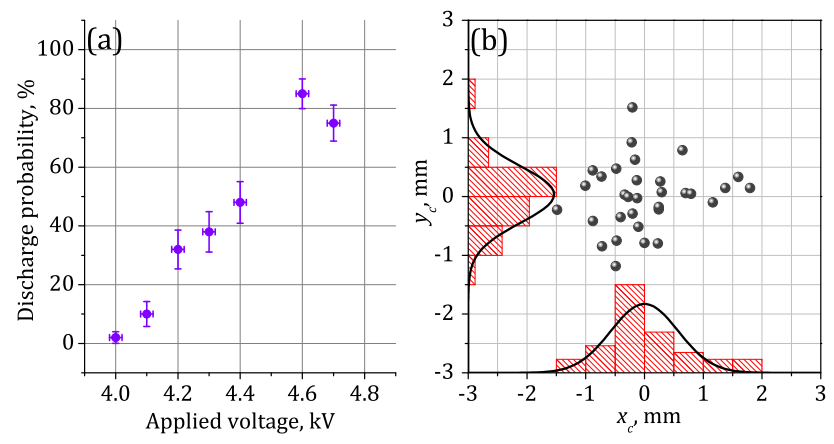

FIG. 3. (a) Experimentally measured dependence of discharge probability on the applied voltage at the distance $z=54 \mathrm{~m}$. (b) Measured wandering of the beam center $\left\{x_{c}, y_{c}\right\}$ at the distance $z=60 \mathrm{~m}$ (spheres). The number of laser shots, for which the beam center $\left\{x_{c}, y_{c}\right\}$ falls within a 0.5 -mm range along either $x$ or $y$-axis (red bars, out of scale), and Gaussian fits of these distributions (black curves).

preserves this transverse size from $50 \mathrm{~m}$ to $80 \mathrm{~m}$ [Fig. 2(a), stars]. The physical reason for this notably stable hot spot diameter is the nonlinear transformation of a femtosecond pulse in the postfilament ${ }^{38,45-48}$. The peak power of a femtosecond pulse in the postfilament is about the critical power for self-focusing in air. The laser beam in the postfilament does not diverge over a long distance, preserves high intensity and exceeds the $0.5-\mathrm{mm}$ diameter of the needle electrode tip [Fig. 1(a)] by a factor of 2-4.

Therefore, the probability of hitting the cathode and initiating the discharge depends on the beam wandering in the transverse direction due to atmospheric turbulence, thermal lensing in amplification system etc. For quantitative characterization of the laser beam wandering, we recorded the beam 
fluence distribution at $z=60 \mathrm{~m}$ in 32 successive laser shots. The "mass centers" $\left\{x_{c}, y_{c}\right\}$ of the measured fluence distributions [spheres in Fig. 3(b)] have the standard deviations along $x$ and $y$ axes of $\sigma_{x}=1.15 \mathrm{~mm}$ and $\sigma_{y}=0.97 \mathrm{~mm}$, respectively.

The simulated spatio-temporal intensity distribution $I(t, r, z)$ on a 100 -m path enables us to find the hot spot size, i.e., the largest radius $r$ at each propagation position $z$ for which the pulse intensity $I(r, t, z)$ exceeds the threshold value $I_{\text {th }}=0.5 \mathrm{TW} / \mathrm{cm}^{2}$ chosen for the reason that the peak pulse intensity is above this value throughout the experimentally found discharge triggering zone, see Fig. 2.

We estimate the probability for the hot spot to illuminate the electrode tip and trigger the discharge by extracting from the simulated beam intensity distribution the area, in which the intensity exceeds $I_{\mathrm{th}}$, and taking into account the beam wandering registered in the experiment [Fig. 3(b), spheres and histograms]. The hot spot center is assumed to be wandering according to a Gaussian distribution with the width increasing linearly with the propagation distance $z: \sigma(z)=$ $\frac{1}{2}\left(\sigma_{x}+\sigma_{y}\right) \times z / 60 \mathrm{~m} \approx 1 \mathrm{~mm} \times z / 60 \mathrm{~m}$. For the electrode tip with the diameter of $0.5 \mathrm{~mm}$ the resulting probability is presented in Fig. 2(a) by the red curve.

In agreement with the experiment, the calculated discharge probability $P$ exceeds $80 \%$ in the 15 -m-long region of the highest intensity of the light channel, which spans from 42 to $57 \mathrm{~m}$ [Fig. 2(a), the red curve]. Further on, for another 15 meters, up to the distance $z \approx 72 \mathrm{~m}$, the discharge is initiated less frequently, however, its probability is still higher than $50 \%$. Beyond $z \approx 72 \mathrm{~m}$ and up to $z \approx 90 \mathrm{~m}$ the discharge probability decreases further due to the transverse beam wandering but remains above $20 \%$. The effective discharge triggering radius, i.e. the largest radius of the hot spot, in which the intensity is above the threshold value $I_{\text {th }}=0.5 \mathrm{TW} / \mathrm{cm}^{2}$, is $0.65 \mathrm{~mm}$. Thus, the large beam background [Fig. 1(a), red color] does not contribute to the discharge triggering.

The nonlinear photoemission $37,49-51$, including the one induced by a femtosecond pump ${ }^{52,53}$, was observed at the intensity in the range of $1-10 \mathrm{GW} / \mathrm{cm}^{2}$, i. e. $2-3$ orders of magnitude lower than the threshold intensity $I_{\text {th }}=0.5 \mathrm{TW} / \mathrm{cm}^{2}$ we used for calculating the hot spot radius and quantifying the probability of cathode tip hitting. As extracted from the simulations, the fluence of the laser pulse imposed on the cathode in our experiment is a factor of $2-10$ below the material ablation threshold, except for the $\sim 0.3$-m zone of high intensity [Fig. 2(b), the black curve at $z \approx 48 \mathrm{~m}$ ]. Indeed, the ablation can be observed at the intensity ${ }^{54}$ close to $I_{\text {th }}=0.5 \mathrm{TW} / \mathrm{cm}^{2}$, however, it requires a light fluence higher than ${ }^{55} \sim 0.5 \mathrm{~J} / \mathrm{cm}^{2}$.

In conclusion, we show that the 90-fs, 744-nm, 6-mJ laser pulses at $10-\mathrm{Hz}$ repetition rate can be used for triggering discharges at the positions of $40-80 \mathrm{~m}$ from laser output. The triggering efficiency approaches $80 \%$ in the $\sim 15$-m-long region including the $\sim 0.3$-m-long plasma filament and postfilament where the pulse intensity is about $5 \mathrm{TW} / \mathrm{cm}^{2}$. Further down the propagation path the probability of the discharge triggering decreases due to the laser beam wandering.

Numerical simulations on a $100-\mathrm{m}$ propagation path in air were used to quantify the pulse intensity in the discharge triggering zone. The threshold intensity of $\sim 0.5 \mathrm{TW} / \mathrm{cm}^{2}$ was used to define the transverse size of the hot spot hitting the cathode tip. The joint usage of the $\sim 0.5 \mathrm{TW} / \mathrm{cm}^{2}$ threshold and the experimentally obtained laser beam center fluctuations yielded the values of the discharge probability, which agree with the experiment.

\section{ACKNOWLEDGMENTS}

This research was supported by Russian Fund for Basic Research (18-52-16020). Foundation for the Advancement of Theoretical Physics and Mathematics "BASIS" (20-2-1-47-1, 19-2-6-261-1).

\section{DATA AVAILABILITY}

The data that support the findings of this study are available from the corresponding author upon reasonable request.

\section{REFERENCES}

${ }^{1}$ V. D. Zvorykin, N. V. Didenko, A. A. Ionin, I. V. Kholin, A. V. Konyashchenko, O. N. Krokhin, A. O. Levchenko, A. O. Mavritskii, G. A. Mesyats, A. G. Molchanov, M. A. Rogulev, L. V. Seleznev, D. V. Sinitsyn, S. Y. Tenyakov, N. N. Ustinovskii, and D. A. Zayarnyi, "Garpun-mtw: A hybrid ti:sapphire/krf laser facility for simultaneous amplification of subpicosecond/nanosecond pulses relevant to fast-ignition icf concept," Laser and Particle Beams 25, 435-451 (2007).

${ }^{2}$ L. Arantchouk, A. Houard, Y. Brelet, J. Carbonnel, J. Larour, Y.-B. Andre, and A. Mysyrowicz, "A simple high-voltage high current spark gap with subnanosecond jitter triggered by femtosecond laser filamentation," Applied Physics Letters 102, 163502 (2013).

${ }^{3}$ R. J. Osborne, J. A. Wehrmeyer, H. P. Trinh, and J. W. Early, "Evaluation and characterization study of dual pulse laser-induced spark (dplis) for rocket engine ignition system application," (American Institute of Aeronautics and Astronautics, 2003).

${ }^{4} \mathrm{C}$. Manfletti, "Laser ignition of an experimental cryogenic reaction and control thruster: Ignition energies," Journal of propulsion and power 30, 952961 (2014).

${ }^{5}$ O. Gurliat, V. Schmidt, O. J. Haidn, and M. Oschwald, "Ignition of cryogenic h 2 /lox sprays," Aerosp. Sci. Technol. 7, 517-531 (2003).

${ }^{6}$ A. Houard, C. D’Amico, Y. Liu, Y. B. Andre, M. Franco, B. Prade, A. Mysyrowicz, E. Salmon, P. Pierlot, and L.-M. Cleon, "High current permanent discharges in air induced by femtosecond laser filamentation," Applied Physics Letters 90, 171501 (2007).

${ }^{7}$ D. Klapas, R. Hackam, and F. A. Benson, "Electric arc power collection for high-speed trains," Proceedings of the IEEE 64, 1699-1715 (1976).

${ }^{8}$ G. Point, L. Arantchouk, E. Thouin, J. Carbonnel, A. Mysyrowicz, and A. Houard, "Long-lived laser-induced arc discharges for energy channeling applications," Scientific Reports 7, 13801 (2017).

${ }^{9}$ S. G. Davydov, A. N. Dolgov, T. I. Kozlovskaya, V. O. Revazov, V. P. Seleznev, and R. K. Yakubov, "Process of commutation of a vacuum electricdischarge gap by laser plasma," Plasma Physics Reports 42, 91-95 (2016).

${ }^{10}$ V. I. Vladimirov, G. M. Malyshev, G. T. Razdobarin, and V. V. Semenov, J. Techn. Phys. 37, 1742 (1967).

${ }^{11}$ A. G. Akmanov, L. A. Rivlin, and V. S. Shildyaev, "Optically initiated directed electric breakdown in a gas," Soviet Phys. JETP Letters 8, 258 (1968).

${ }^{12}$ J. R. Vaill, D. A. Tidman, T. D. Wilkerson, and D. W. Koopman, "Propagation of high-voltage streamers along laser-induced ionization trails," Applied Physics Letters 17, 20-22 (1970).

${ }^{13}$ A. H. Guenther and J. R. Bettis, "A review of laser-triggered switching," Proceedings of the IEEE 59, 689-697 (1971). 
${ }^{14}$ D. W. Koopman and T. D. Wilkerson, "Channeling of an ionizing electrical streamer by a laser beam," Journal of Applied Physics 42, 1883-1886 (1971).

${ }^{15}$ L. M. Ball, "The laser lightning rod system: thunderstorm domestication," Applied optics 13, 2292-2295 (1974).

${ }^{16}$ L. M. Ball, "Laser lightning rod system," U.S. Patent No. 4,017,767 (12 Apr. 1977).

${ }^{17}$ S. Uchida, Y. Shimada, H. Yasuda, S. Motokoshi, C. Yamanaka, T. Yamanaka, Z.-I. Kawasaki, and K. Tsubakimoto, "Laser-triggered lightning in field experiments," J. of Opt. Tech. 66, 199 (1999).

${ }^{18}$ A. Braun, G. Korn, X. Liu, D. Du, J. Squier, and G. Mourou, "Selfchanneling of high-peak-power femtosecond laser pulses in air," Optics letters 20, 73 (1995).

${ }^{19}$ X. M. Zhao, J. C. Diels, C. Y. Wang, and J. M. Elizondo, "Femtosecond ultraviolet laser pulse induced lightning discharges in gases," IEEE Journal of Quantum Electronics 31, 599-612 (1995).

${ }^{20} \mathrm{~S}$. L. Chin and K. Miyazaki, "A comment on lightning control using a femtosecond laser,” Japan. J. Appl. Phys. 38, 2011 (1999).

${ }^{21}$ D. Comtois, C. Y. Chien, A. Desparois, F. Génin, G. Jarry, T. W. Johnston, J.-C. Kieffer, B. La Fontaine, F. Martin, R. Mawassi, H. Pépin, F. A. M. Rizk, F. Vidal, P. Couture, H. P. Mercure, C. Potvin, A. BondiouClergerie, and I. Gallimberti, "Triggering and guiding leader discharges using a plasma channel created by an ultrashort laser pulse," Applied Physics Letters 76, 819-821 (2000).

${ }^{22}$ S. Tzortzakis, B. Prade, M. Franco, A. Mysyrowicz, S. Huller, and P. Mora, "Femtosecond laser-guided electric discharge in air," Physical Review E 64, 057401 (2001).

${ }^{23}$ M. Rodriguez, R. Sauerbrey, H. Wille, L. Woeste, T. Fujii, Y. B. André, A. Mysyrowicz, L. Klingbeil, K. Rethmeier, W. Kalkner, J. Kasparian, E. Salmon, J. Yu, and J.-P. Wolf, "Triggering and guiding megavolt discharges by use of laser-induced ionized filaments," Optics letters 27, 772774 (2002).

${ }^{24}$ D. F. Gordon, A. Ting, R. F. Hubbard, E. Briscoe, C. Manka, S. P. Slinker, A. P. Baronavski, H. D. Ladouceur, P. W. Grounds, and P. G. Girardi, "Streamerless guided electric discharges triggered by femtosecond laser filaments," Physics of Plasmas 10, 4530-4538 (2003).

${ }^{25}$ A. Ionin, S. Kudryashov, A. Levchenko, L. Seleznev, A. Shutov, D. Sinitsyn, I. Smetanin, N. Ustinovsky, and V. Zvorykin, "Triggering and guiding electric discharge by a train of ultraviolet picosecond pulses combined with a long ultraviolet pulse," Applied Physics Letters 100, 104105 (2012).

${ }^{26}$ E. Schubert, A. Rastegari, C. Feng, D. Mongin, B. Kamer, J. Kasparian, J.-P. Wolf, L. Arissian, and J.-C. Diels, "Hv discharge acceleration by sequences of uv laser filaments with visible and near-infrared pulses," New J. Phys. 19, 123040 (2017).

${ }^{27}$ L. Arantchouk, G. Point, Y. Brelet, B. Prade, J. Carbonnel, Y.-B. André, A. Mysyrowicz, and A. Houard, "Large scale tesla coil guided discharges initiated by femtosecond laser filamentation in air," J. Appl. Phys. 116, 013303 (2014).

${ }^{28}$ F. Theberge, J.-F. Daigle, J.-C. Kieffer, F. Vidal, and M. Chateauneuf, "Laser-guided energetic discharges over large air gaps by electric-field enhanced plasma filaments," Scientific reports 7, 1-8 (2017).

${ }^{29}$ H. Wille, M. Rodríguez, J. Kasparian, D. Mondelain, J. Yu, A. Mysyrowicz, R. Sauerbrey, J.-P. Wolf, and L. Woeste, "Teramobile: a mobile femtosecond-terawatt laser and detection system," Eur. Phys. J. Appl. Phys. 20, 183-190 (2002).

${ }^{30}$ J. Kasparian, R. Ackermann, Y.-B. André, G. Méchain, G. Méjean, B. Prade, P. Rohwetter, E. Salmon, K. Stelmaszczyk, J. Yu, et al., "Electric events synchronized with laser filaments in thunderclouds," Optics express 16, 5757-5763 (2008).

${ }^{31}$ T. Produit, P. Walch, C. Herkommer, A. Mostajabi, M. Moret, U. Andral, A. Sunjerga, M. Azadifar, Y.-B. André, B. Mahieu, W. Haas, B. Esmiller, G. Fournier, P. Krötz, T. Metzger, K. Michel, A. Mysyrowicz, M. Rubinstein, F. Rachidi, J. Kasparian, J.-P. Wolf, and A. Houard, "The laser lightning rod project,” Eur. Phys. J. Appl. Phys. 91, 10504 (2021).

${ }^{32} \mathrm{P}$. Polynkin, "Multi-pulse scheme for laser-guided electrical breakdown of air," Applied Physics Letters 111, 161102 (2017).

${ }^{33}$ S. Chin, A. Talebpour, J. Yang, S. Petit, V. Kandidov, O. Kosareva, and M. Tamarov, "Filamentation of femtosecond laser pulses in turbulent air," Appl. Phys. B 74, 67-76 (2002).

${ }^{34}$ G. Tamošauskas, L. L. Šaulys, A. Dubietis, and A. Piskarskas, "Small scale laser-triggered electrical discharges and their application to character- ization of plasma channel induced by light filaments," Lithuanian Journal of Physics 45, 37-42 (2005).

${ }^{35}$ B. La Fontaine, D. Comtois, C.-Y. Chien, A. Desparois, F. Genin, G. Jarry, T. Johnston, J.-C. Kieffer, F. Martin, R. Mawassi, et al., "Guiding largescale spark discharges with ultrashort pulse laser filaments," J. Appl. Phys. 88, 610-615 (2000).

${ }^{36}$ M. Clerici, Y. Hu, P. Lassonde, C. Milian, A. Couairon, D. Christodoulides, Z. Chen, L. Razzari, F. Vidal, F. Légaré, D. Faccio, and R. Morandotti, "Laser-assisted guiding of electric discharges around objects," Science Advances 1, e1400111-e1400111 (2015).

${ }^{37}$ S. Chin, "Direct experimental evidence of multiphoton ionization of impurities as the initiation process of laser-induced gas breakdown," Canadian Journal of Physics 48, 1314-1317 (1970).

${ }^{38}$ O. Kosareva, N. Panov, D. Shipilo, D. Mokrousova, I. Nikolaeva, E. Mitina, A. Koribut, A. Reutov, G. Rizaev, A. Couairon, A. Houard, D. Skryabin, A. Saletskiy, A. Savel'ev, L. Seleznev, A. Ionin, and S. L. Chin, "Postfilament supercontinuum on $100 \mathrm{~m}$ path in air," Opt. Lett. 46, 1125-1128 (2021).

${ }^{39}$ M. Kolesik and J. V. Moloney, "Nonlinear optical pulse propagation simulation: From Maxwell's to unidirectional equations," Phys. Rev. E 70, 036604 (2004).

${ }^{40}$ N. A. Panov, D. E. Shipilo, A. M. Saletsky, W. Liu, P. G. Polynkin, and O. G. Kosareva, "Nonlinear transparency window for ultraintense femtosecond laser pulses in the atmosphere," Phys. Rev. A 100, 023832 (2019).

${ }^{41}$ J. Kasparian, R. Sauerbrey, and S. L. Chin, "The critical laser intensity of self-guided light filaments in air," Appl. Phys. B 71, 877 (2000).

${ }^{42} \mathrm{X}$. Ling, R. Jayaratne, and L. Morawska, "Air ion concentrations in various urban outdoor environments," Atmospheric Environment 44, 21862193 (2010).

${ }^{43}$ J. Allan, H. Edels, and D. Whittaker, "Post-arc temperature decay," Proceedings of the Physical Society (1958-1967) 78, 948 (1961).

${ }^{44} \mathrm{H}$. Edels and J. Holme, "Measurements of the decay of arc column metperature following interruption," Br. J. Appl. Phys. 17, 1595 (1966).

${ }^{45}$ G. Méchain, A. Couairon, Y.-B. André, C. D’Amico, M. Franco, B. Prade, S. Tzortzakis, A. Mysyrowicz, and R. Sauerbrey, "Long-range selfchanneling of infrared laser pulses in air: a new propagation regime without ionization," Appl. Phys. B 79, 379-382 (2004).

${ }^{46}$ J.-F. Daigle, O. Kosareva, N. Panov, T.-J. Wang, S. Hosseini, S. Yuan, G. Roy, and S. Chin, "Formation and evolution of intense, postfilamentation, ionization-free low divergence beams," Opt. Comm. 284, 3601-3606 (2011).

${ }^{47}$ J. Peñano, B. Hafizi, A. Ting, and M. Helle, "Theoretical and numerical investigation of filament onset distance in atmospheric turbulence," J. Opt. Soc. Am. B 31, 963-971 (2014).

${ }^{48}$ G. DiComo, M. Helle, D. Kaganovich, A. Schmitt-Sody, J. Elle, and J. Peñano, "Nonlinear self-channeling of high-power lasers through controlled atmospheric turbulence," J. Opt. Soc. Am. B 37, 797-803 (2020).

${ }^{49}$ F. Bunkin and M. Fedorov, "Cold emission of electrons from the surface of a metal in a strong radiation field," Sov. Phys. JETP 21, 896 (1965).

${ }^{50}$ G. Farkas, S. L. Chin, P. Galarneau, and F. Yergeau, "A new type of intense $\mathrm{CO}_{2}$ laser induced electron emission from a gold surface," Optics Communications 48, 275-278 (1983).

${ }^{51}$ L. Lompre, J. Thebault, and G. Farkas, "Intensity and polarization effects of a single 30-psec laser pulse on five-photon surface photoeffect of gold," Appl. Phys. Lett. 27, 110-112 (1975).

${ }^{52}$ W. Fann, R. Storz, and J. Bokor, "Observation of above-threshold multiphoton photoelectric emission from image-potential surface states," Physical Review B 44, 10980 (1991).

${ }^{53}$ M. Aeschlimann, C. Schmuttenmaer, H. Elsayed-Ali, R. Miller, J. Cao, Y. Gao, and D. Mantell, "Observation of surface enhanced multiphoton photoemission from metal surfaces in the short pulse limit," The Journal of chemical physics 102, 8606-8613 (1995).

${ }^{54}$ J. Girardeau-Montaut and C. Girardeau-Montaut, "Theory of ultrashort nonlinear multiphoton photoelectric emission from metals," Physical Review B 51, 13560 (1995).

${ }^{55}$ P. Pronko, S. Dutta, D. Du, and R. Singh, "Thermophysical effects in laser processing of materials with picosecond and femtosecond pulses," Journal of Applied Physics 78, 6233-6240 (1995). 


\section{$5 \mathrm{~mm}$}

(a)
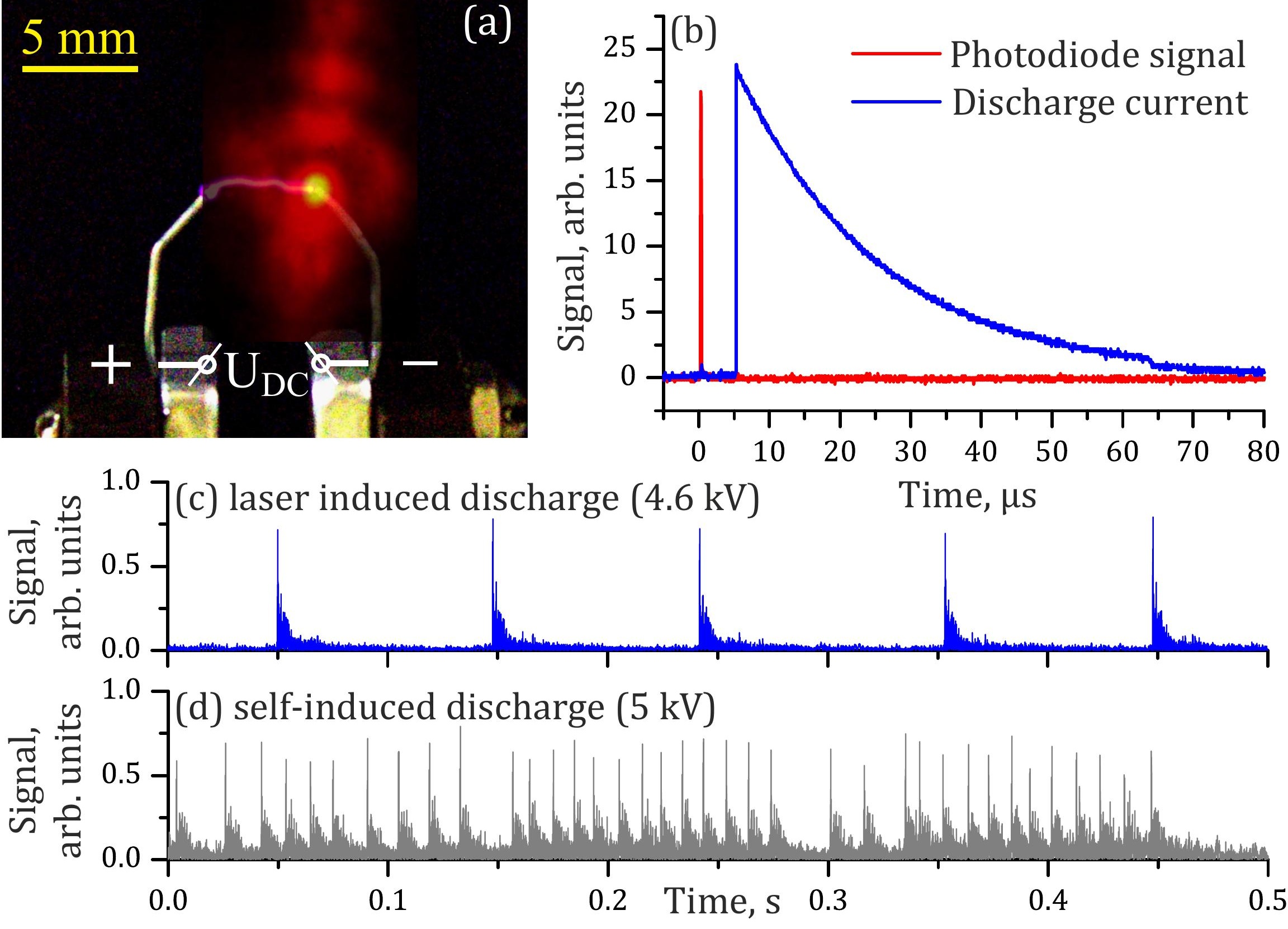


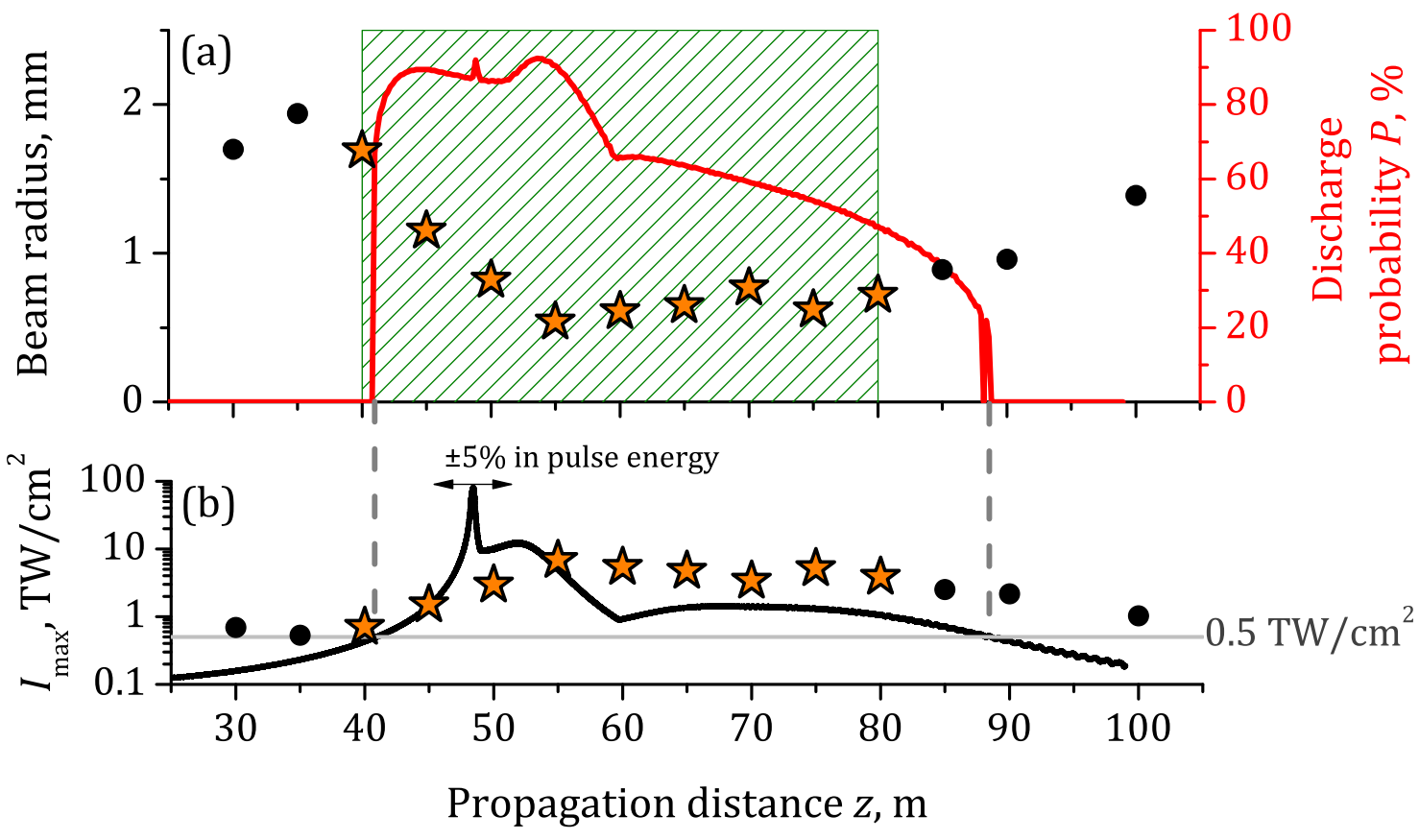


